Praxis Essay

\title{
Introducing Critical Race Media Literacy in an Undergraduate Education Course about Technology and Arts-Based Inquiry
}

\author{
Darnel Degand \\ University of California, Davis \\ U.S.A.
}

ABSTRACT: Critical race media literacy refers to the ability to (a) recognize negative stereotypical portrayals of historically oppressed groups in media,

(b) question media producers' intentions, and (c) produce media content that does not perpetuate stereotypes. Critical race media literacy can be taught in many college classes, but an undergraduate education course that utilizes a multimodal approach to teach students about the various ways learning occurs in the digital age is an excellent opportunity to develop this skill in undergraduates. This article provides specific examples of teaching techniques used in an undergraduate course about technological media and arts-based inquiry.

KEYWORDS: Critical Race Theory, Critical Media Literacy, Culturally Relevant Media Production, Multiliteracies, Technology Integration

\author{
Critical (Race) Media Literacy \\ Integrating Technology and Arts-Based Inquiry into Classrooms \\ Critical Race Media Literacy in an Undergraduate Education Course \\ Conclusion \\ References \\ Author Contact
}

As new and diverse forms of media and technology permeate our daily lives, multiliteracies (New London Group, 1996) and arts-based inquiry (Kraehe \& Brown, 2011) are increasingly recognized and valued in educational spaces (Rhoades, 2020; Wargo, 2019). Multiliteracies is a multimodal pedagogy that "focuses on modes of representation much broader than language alone" (New London Group, 1996, p. 64). The New London Group (1996), a multinational coalition of 10 educational media researchers, introduced the concept of multiliteracies because they recognized "the increasing multiplicity and integration of significant modes of meaning-making, where the textual is also related to the visual, the audio, the spatial, the behavioral, and so on" (p. 64). They also use the term multiliteracies as a way to recognize "linguistic differences and cultural differences [that have] now become central to the pragmatics of our working, civic, and private lives" (New London Group, 1996, p. 64). As our societies continue to become increasingly multimodal and culturally diverse, educational spaces must also reflect these changes. I contend that students will be better prepared for conflicts, collaborations, 
and growth in our increasingly multicultural societies when they are given the opportunity to engage in genuine social exchanges, disagreements, debates, and resolutions with others in multicultural educational spaces. Arts-based inquiry can serve as a mode of communication and education during these social dialogues. "Whether visual, performance-based, literary, digital, or a combination of these, arts-based inquiry is a process one undertakes to transform prior understandings and misunderstandings through the manipulation of material and symbolic tools and the reconstruction of social and cultural meanings" (Kraehe \& Brown, 2011, p. 491). Multiliteracies and arts-based inquiry are especially important given the ways media can produce partialities and biases that perpetuate stereotypes against historically oppressed groups.

Yosso (2002) argues that "racism, as well as gender- and class-based oppression, in the United States is perpetuated in the form of entertainment media (film, advertising, television, and magazines)" (p. 52). Wealthy White men are portrayed as archetypes of professional success due to biased assumptions about their innate proficiency in various industries (including behind-the-scenes during media production), whereas other groups, especially people of color from lower socioeconomic circumstances, are rarely seen in these roles or are depicted as antagonistic and unfit for many professions. As a result, women and people of color are less likely to be accepted into media production spaces while the perspectives of White men continue to be at the center of most media narratives (Yuen, 2016). Teachers who lack the skills needed to interrogate the media landscape are at risk of attributing greater importance to White and Eurocentric aesthetics and stories, and accordingly of privileging the work of students that preference those aesthetics and narratives (Degand, 2019). Conversely, students of pre-service teachers who are equipped to combat discrimination in the classroom have the potential to become the next generation of creators who can disrupt the media landscape's status quo.

Yosso (2002) proposes the use of critical race media literacy (CRML) as a pedagogical response to the influences of sexism and racism in the classroom. As noted by Hawkman and Van Horn (2019), "Critical race media literacy calls students to recognize the problematic ways people of color are represented in various media outlets while questioning the intentions behind such representations and working toward creating more-just representations in the media" (p. 119). CRML is informed by critical media literacy (CML) and critical race theory (CRT). CML utilizes "media as a pedagogical tool in the struggle to raise social consciousness and work toward social justice" (Yosso, 2002, p. 60). CRT privileges "the experiential knowledge of people of color as critical ways of knowing and naming racism and other forms of oppression" (Fernández, 2002, p. 48). In particular, CRT demands that we acknowledge how colorblind meritocratic approaches to justice and education can perpetuate social inequities. Founding CRT scholars borrowed concepts from critical legal studies and radical feminism to demonstrate the various ways that racism and patriarchy are unacknowledged, yet "normal," aspects of our society (Delgado \& Stefancic, 2017). I posit that the employment of these CRT tenets during media analyses can encourage a more complete media literacy among pre-service teachers. 
CRML can be taught in many college classes, but an undergraduate education course that utilizes multiliteracies' multimodal approach to teach students about the various ways learning happens in the digital age is an excellent opportunity to develop this competency in undergraduates. Multimodal pedagogy's use of various media aligns well with CML's capability to "[expand] the notion of literacy to include different forms of mass communication, popular culture, and new technologies" (Kellner \& Share, 2007, p. 60). Multimodal pedagogy also connects well with CML's ability to "[empower] students to create their own messages that can challenge media texts and narratives" (p. 60).

This article establishes the differences between media literacy (ML), CML, and CRML. Next, it introduces data from other studies about the multimodal educational experiences of teachers and students. Afterward, I share descriptions of practical CRML teaching techniques that I applied in an undergraduate college education course, and the artefacts pre-service teachers produced as a result, to show the benefits of this pedagogy.

\section{Critical (Race) Media Literacy}

To understand CRML (and how it differs from $M L$ and $C M L$ ), we must first discuss the theoretical framework that undergirds it: CRT. CRT has five basic tenets that can inform media discussions and critical analyses:

1. Racism exists in implicit and explicit forms throughout society.

2. Racism persists because high income groups and working-class Whites benefit materially or psychically from it.

3. Race is a social construct.

4. Essentializing an individual to a unitary identity is reductive and encourages stereotyping.

5. Counterstories about marginalized communities are valuable narratives that can challenge overrepresented perspectives in mainstream media. (Delgado \& Stefancic, 2017)

These tenets contextualize media experiences and social interactions through statements about our society and the various ways race, racism, and other forms of discrimination influence our lives. CRT is a key component in CRML, but it is not a requirement in $\mathrm{ML}$ and $\mathrm{CML}$.

The terms "media literacy" and "critical media literacy" are often used interchangeably, but they are not the same. The "critical" component is often either missing or deficient in the definitions and practices of ML promoted by most organizations and individuals (Ligocki, 2017). Moreover, CRML is a specific approach to CML that utilizes CRT as its guide during examinations of multiple intersecting forms of discrimination within media consumption and media production experiences. In the United States, ML is most often defined as "the ability to access, analyze, evaluate and create media in a variety of forms" (Center 
for Media Literacy, n.d., para.1). Kellner and Share's (2007) definition of CML demands an approach that goes further than ML:

Critical media literacy is an educational response that expands the notion of literacy to include different forms of mass communication, popular culture, and new technologies. It deepens the potential of literacy education to critically analyze relationships between media and audiences, information, and power. Along with this mainstream analysis, alternative media production empowers students to create their own messages that can challenge media texts and narratives. (p. 60)

As seen when comparing their definitions, ML refers to several essential skills, but leaves out the ability to critically analyze and produce media that challenge the status quo, as required by CML (and CRML). Kellner and Share (2007) argue that varying interpretations of $M L$ can inspire educators to take (a) a protectionist approach, (b) a media literacy movement approach, or (c) a media arts education approach when teaching media education. Yet none of these approaches proposes to teach students how social power imbalances and inequities contribute to the persistence of problematic media content and antisocial interactions. Furthermore, these approaches do not encourage students to create media experiences that critique and push back against the status quo. The "critical" aspect of $\mathrm{CML}$ is a deliberate and action-oriented requirement that must be included in the educational experience, while the inclusion of CRT in the CRML approach provides students and teachers with an analytical lens to use during their media analyses.

According to Share (2015), there are five core concepts of CML:

1. All Media Messages Are "Constructed."

2. Media Messages Are Constructed Using a Creative Language With its Own Rules.

3. Different People Experience the Same Media Message Differently.

4. Media Have Embedded Values and Points of View.

5. Media Are Organized to Gain Profit and/or Power. (p. 22)

The Center for Media Literacy's MediaLit Kit ${ }^{\mathrm{TM}}\left(\mathrm{CMLMK}^{\mathrm{TM}}\right)$ framework pairs these CML concepts with key questions that educators can pose to students during media consumption experiences:

1. Who created this message?

2. What techniques are used to attract my attention?

3. How might different people understand this message differently from me?

4. What lifestyles, values, and points of view are represented in, or omitted from, this message?

5. Why was this message sent? (Share, 2015, p. 223) 
A CRML approach to teaching uses CRT's tenets as a foundational guide when students and teachers seek answers to CMLMK ${ }^{\text {TM's }}$ key questions. CRT's tenets inform the lenses used by teachers and students as they formulate multimodal responses to CMLMK ${ }^{\mathrm{TM}}$ 's key questions. The following five sections explore how $\mathrm{CMLMK}^{\mathrm{TM}}$ 's framework can be informed by CRT's tenets to provide students with a CRML experience:

\section{Who Created this Message?}

Students should be taught that media messages are 'constructed' by individuals with different beliefs, complementary or divergent objectives, and varying levels of expertise in an assortment of subject matters (including media). A social media campaign by the New York City Police Department (NYPD) serves as a case in point. The \#myNYPD hashtag had been launched on Twitter by the NYPD in an effort to portray themselves positively. They achieved brief success through participation from citizens who viewed the police positively. However, this changed when critiques of police violence were also shared. "What started as a public relations campaign quickly turned into an online protest as thousands of citizens appropriated the \#myNYPD hashtag to highlight instances of police brutality, abuse, and racial profiling" (Jackson \& Welles, 2015, p. 932). This failed campaign displayed a deficiency in the NYPD's understanding of hashtags. Hashtags are accessible to everyone on social media. Users of \#myNYPD posted messages that were based on their experiences with the NYPD. The NYPD did not anticipate that this user-generated content would include both positive and negative encounters.

A very small percentage of citizens have access to mass media broadcasting resources. This privilege enables them to broadcast their messages to millions. A CRML approach to answering the question "Who created this mass media message?" is guided by CRT's acknowledgement of the implicit and explicit forms of discrimination that cause most mainstream media production spaces to be predominately White. It is also guided by the belief that discrimination persists because privileged groups benefit materially and psychically from it. White people continue to be overrepresented in mass media workspaces because the mass media messages they author often reinforce biased beliefs that favor Whites. For example, protagonists continue to be overwhelmingly White while antagonists are consistently depicted as people of color (Yuen, 2016).

\section{What Techniques Are Used?}

The constantly evolving nature of existing mediums and new technologies requires us to repeatedly question and examine the techniques media producers use to hold our attention. The deconstruction of media messages involves constant negotiations between what we are presented, what we are told is the purpose of the presented message, the origins of that message, and the resources (e.g., time, knowledge, experience, financials, tools) we have available to us during our investigations of the techniques. While working on a radio documentary about racial stereotypes, students in Doerr-Stevens and Buckley-Marudas' (2019) study "had to harness sound editing software to combine elements of music, sound 
effects, dialogue and silence" (p. 106). They had the opportunity to experiment with these sound editing techniques for their radio documentary because their school provided them with computers, audio software, and focused time during class to make progress on the assignment. Similarly, while working on their end-ofsemester social media projects, Sohoni's (2019) undergraduates examined techniques that are used for "keeping audience attention (length of video, pacing, and tone), determining the target audience, and what might engage that audience (for instance, sarcasm, empathy, and modes of persuasion such as pathos, ethos, and logos)" (p. 394). Their professor made space and time for them to deconstruct past social media messages, and encouraged them to "draw on their informal expertise as consumers of social media" (p. 394) during their analyses of these messages. They had the opportunity to engage in these discussions about social media presentation techniques because their professor assigned this activity as an alternative to their final paper essay and presentation assignment.

A CRML approach to answering the question "What techniques are used?" is informed by CRT's tenet concerning the harms of racial essentialism and its role in stereotyping. Students should learn that each medium's constraints (e.g., the 30-second time limit in television commercials; the limited space shared by text and images in a comics panel) encourages media producers to use shortcuts, symbolism, and shorthand for quick and efficient communication. Students should also explore how these techniques can inspire limiting portrayals of genders, races, and other social categorizations. For example, they could ask how social constructions of race inform biased beliefs that lead media producers to typecast dark-skinned actors as antagonist.

\section{How Might Different People Understand this Message?}

A multicultural education paired with a CML lens can assist us in understanding how and why different people might experience the same media message differently. A CRML approach encourages students to examine how the media experiences of individuals from marginalized groups might differ from those of individuals from privileged groups who often serve as the target audience for our media content. The \#myNYPD public relations campaign is an excellent example of this (Jackson \& Wells, 2015). Their target audience only included citizens who viewed the NYPD in a positive light. They disregarded how victims of police violence (and their advocates) might react to this campaign. Conversely, undergraduates in Sohoni's (2019) study were forward-thinking as they considered "how to best craft [their social media project] content to the intended audience, and whether they [foresaw] any potential criticism or backlash to the material that should be addressed" (p. 394). They deliberated over potential responses to their project topics (e.g., Black Lives Matters, White privilege, the war on drugs, etc.) and they designed their presentations around these conversations.

\section{Whose Lifestyles, Values, and Perspectives Are Included or Omitted?}

Students must acquire the ability to understand the embedded points of views in media messages. They should engage in discussions about the sociohistorical origins of media stereotypes (Bogle, 2016). Many teachers use 
CML approaches to engage their students in discussions about these topics. For instance, in a high school ethnic studies class, "students read about the demonization and scapegoating of youth perpetuated by the mass media. The text that students read [addressed] the concern that mass media [do] not highlight the realities that affect youth and their future" (Morrell, Dueñas, Garcia, \& Lopez, 2013, p. 87). In a similar vein, a CRML approach can further inspire students to ask how and why the social experiences of people from historically oppressed groups are devalued, omitted, or marginalized by mass media institutions. It requires that we acknowledge the existence of explicitly and implicitly racist messages in our media. Privileged groups in society regularly enjoy media depictions of themselves that consist of characters with a wide-array of personalities, traits, and tastes. Yet, historically oppressed groups continue to be portrayed in a limited number of stereotypical roles (Bogle, 2016). Global Action Project (n.d.) specifically works to create counterstories that uplift historically oppressed groups by developing "the capacities and skills of youth most affected by injustice, to create powerful media, cultural expression, and social change. GAP provides effective media-arts programming to youth from low-income, new immigrant, and TLGBQ (Transgender, Lesbian, Gay, Bi, Queer) communities" (para. 1) with the aim of addressing the gaps in representation in mass media. If students consider the many ways one message can be interpreted by people with varying perspectives, values, and lifestyles, it might encourage them to carefully consider the messages they wish to communicate, and to empathize with their audience in an attempt to best communicate with them.

\section{Why Was this Message Sent?}

CML requires that students recognize how mass media is influenced by capitalistic interests. Mass media is distributed across multiple channels on many platforms (e.g., newspaper, television, radio, and social media). This might appear to suggest that a multitude of perspectives and free speech are welcome and available across all of the channels. Unfortunately, this is not the case. The companies that own these platforms are consolidated under a limited number of transnational corporations (Bagdikian, 2004). Their financial objectives dictate the nature and content of the messages communicated to us.

When asking "Why was this message sent?" students should learn how overt and hidden forms of advertising can play a role in the perpetuation of social inequities, and also how similar media can promote empathy in kind. Students in a high school ethnic studies course, for example, evaluated music videos and "found that mainstream hip hop music that targets communities of color hails, celebrates, and reproduces violence, misogyny, sexism, and a desire for materialism" (Morrell et al., 2013, p. 89). However, they also discussed more positive forms of rap music that celebrate diversity and encourage listeners to challenge oppressive systemic ideas and practices. A CRML approach requires us to remember that high income groups and working-class Whites are incentivized to patronize an overabundance of mainstream media that reinforce ideas that materially or psychically benefit them and their beliefs. Mass media encourage the public to accept the existing status quo by depicting classist content. Media 
portrayals of individuals from poor communities that are contrasted with media narratives about wealthy individuals often reinforce harmful meritocratic and materialistic viewpoints (Butsch, 2011). These messages are also reinforced by the carefully crafted public social lives of various media personalities (Dench, 2006).

\section{Integrating Technology and Arts-Based Inquiry into Classrooms}

Undergraduate students enter college with varied experiences around media and technology (Bennett \& Maton, 2010). The types of instructional technology and media experiences they receive during their college years are dependent on their chosen majors and their professors' technology preferences. The major they select is influenced by various factors, such as confidence, current skill levels, personal aspirations, degree of difficulty, expected financial returns, family expectations, social norms, and college offerings (Geyfman, Force, \& Davis, 2015; Monaghan \& Jang, 2017). These are all important factors to consider when designing an undergraduate education course about how to incorporate technology and media into classrooms.

Students majoring or minoring in Education are enrolled in undergraduate courses that prepare them for work in various contexts (e.g., K-12 classrooms, higher education settings, or government policy). Unfortunately, studies show that many teachers struggle to integrate new technological media into their classrooms (Blume, 2020; Hew \& Tan, 2016). The cost of technology and the skills required to use it are important factors to consider when identifying impediments to improved technology integration, but research also suggests that teachers' attitudes about technology (Cullen \& Green, 2011) and their personal pedagogical beliefs (Rehmat \& Bailey, 2014) play a stronger role in influencing if and how they choose to integrate technologies into their lessons.

Aspiring teachers, in-service educators, and other professionals (e.g., higher education administrators and policymakers) who have not been encouraged to experiment with technology and media may lack the confidence needed to promote their use in classrooms. Giles (2019) argues: "Without selfconfidence, teacher candidates will most likely not incorporate technology into their classroom and therefore the teacher's students will not be exposed to technology" (p. 363). Some undergraduate students who are enrolled in education courses might never teach in a classroom. But helping them develop a positive attitude about technology, media, and education is still worthwhile because it is relevant in other professional contexts, such as during the onboarding of new employees at a Fortune 100 company (Depura \& Garg, 2012). Furthermore, some students may go on to become policymakers who can influence decisions that either support or inhibit technology use in the classroom.

Pedagogical approaches can also influence educators' decisions concerning technology in the classroom. Tondeur, Braak, Ertmer, and OttenbreitLeftwich (2017) argue that educational professionals with strong traditional or teacher-centered beliefs (i.e., high importance on student discipline, morals, and 
other behaviorist-related teaching concerns), "do not perceive technology as being essential to the teaching and learning process" (p. 569). Instead, they found a bidirectional relationship between teachers who adopted student-centered beliefs (an emphasis on students' interests) and the likelihood that these teachers would use technology in their classrooms (Tondeur et al., 2017).

The likelihood that an educator will use technology in their classroom is not limited to their pre-service educational experiences. Multiple scholars argue that ongoing in-service teacher training on how to integrate technology and media into the classroom needs to be a systemic, systematic, and iterative process that accounts for teachers' current pedagogical approaches and practices (Kopcha, 2010; Polly, Mims, Shephard, \& Inan, 2010; Tondeur et al., 2016, 2017). In the next section, I offer specific examples of CRML teaching techniques that I used in an undergraduate education course.

\section{Critical Race Media Literacy in an Undergraduate Education Course}

Undergraduate education courses that focus on the use of educational technologies and media provide instructors with excellent opportunities to teach pre-service teachers and other aspiring educational professionals about CRML. This instruction is especially important as demand grows for more K-12 technology and media instruction (Blikstein, 2018; National Coalition for Core Arts Standards, 2018). These students will need educational technology and media experiences that push back against the idea that science, technology, engineering, arts, and math (STEAM) are the domains of White and Asian men (Hansen et al., 2017). The following five sections provide examples of how I use the CMLMK ${ }^{\text {TM }}$ framework as a guide in my CRML approaches to teaching at a Northern California public university. The examples are from my undergraduate Education course about instructional technologies and arts-based inquiry.

\section{Who Created this Message?}

An undergraduate education course that teaches aspiring educational professionals how to integrate technology and media into a classroom should demystify the media production process by ensuring its students understand that all media messages are "constructed" by people. Students should learn that there are various roles played by different individuals during the production process. With this in mind, I ask my students to identify and discuss the authors and the credited producers from their media assignments (e.g., readings, podcasts, videos, games). I also encourage them to cite and reference the content they discuss in their semiweekly writing assignments.

The temporal and environmental contexts that influence those messages are also emphasized. We use critical race theory as a lens to reflect on the overrepresentation of White men in Hollywood and how racism and sexism limit the number of women and people of color accepted into media production spaces (Smith, Choueiti, \& Pieper, 2016; Yuen, 2016). Moreover, I inform them that they are also capable of telling stories through media. I warm them up to the idea of 
creative thinking by having them participate in "improv" activities. These activities are styled after improvisational comedy shows where an audience (the class, in this instance) introduces words to actors (the students in front of the class) and they spontaneously adapt their performance to each word prompt (Halverson, 2011).

\section{What Techniques Are Used?}

Educators should encourage students to experiment with production techniques while creating their own media. As Halverson (2011) states,

If we are truly concerned with producing the kinds of $21^{\text {st }}$ century citizens in this country who will lead the way worldwide in creativity and innovation, we need to teach creativity and innovation. We need to teach young people how to make things, and make things on their own. (2:32)

While considering this, the students and I discuss how producers use different techniques in each medium to capture the attention of consumers. For example, we review the TED Radio Hour "Manipulation" episode and explore the topics covered during that show (e.g., algorithms, fake news, false memories) (Raz, 2017). We also discuss the use of harmful stereotypes in comic books, movies, and cartoons. For example, the diverse range of skin tones among all the heroes and villains of the cartoon, Avatar: The Last Airbender (2005-2008), are contrasted with its movie adaptation, The Last Airbender (2010), in which all protagonist are played by White actors while all villains are played by darker-skinned actors.

Students are given the opportunity to submit their midterm and final exams in one of four different mediums: paper essay, graphic narrative, audio podcast, or video essay. There is lab time set aside during classes to discuss and experiment with the techniques they observe during their analyses of various comics, videos, games, and podcasts. I provide resources on how to create comics, video essays, and podcasts (Edith Cowan University, 2019; Hicks, Winnick, \& Gonchar, 2019) and instruct students to follow APA formatting rules when citing and referencing the sources that support their arguments. I provide them with a link to the Owl Purdue Online Writing Lab website (Purdue University, n.d.) and I direct them on how to apply the rules in each medium. For video essays, they state the author's last name and the year of the referenced material. They also insert a caption at the corner of their video with this information (see Figure 1). For graphic narratives, they are directed to use an asterisk in the text of the story followed by an APAstyle citation in a corner of the comic panel. Figures 2-5 provide examples of students' graphic narrative submissions. Student podcasters cite their sources by stating the author name(s); the year of the referenced content; and, when necessary, the page number(s) or timestamp. For example, while quoting a source, one student stated: "On page 13 of their 2018 article, Mirra, Morrell, and Filipiak said 'youth were not content to merely consume media ..."' All students, regardless of the medium they choose, submit a separate reference page. 


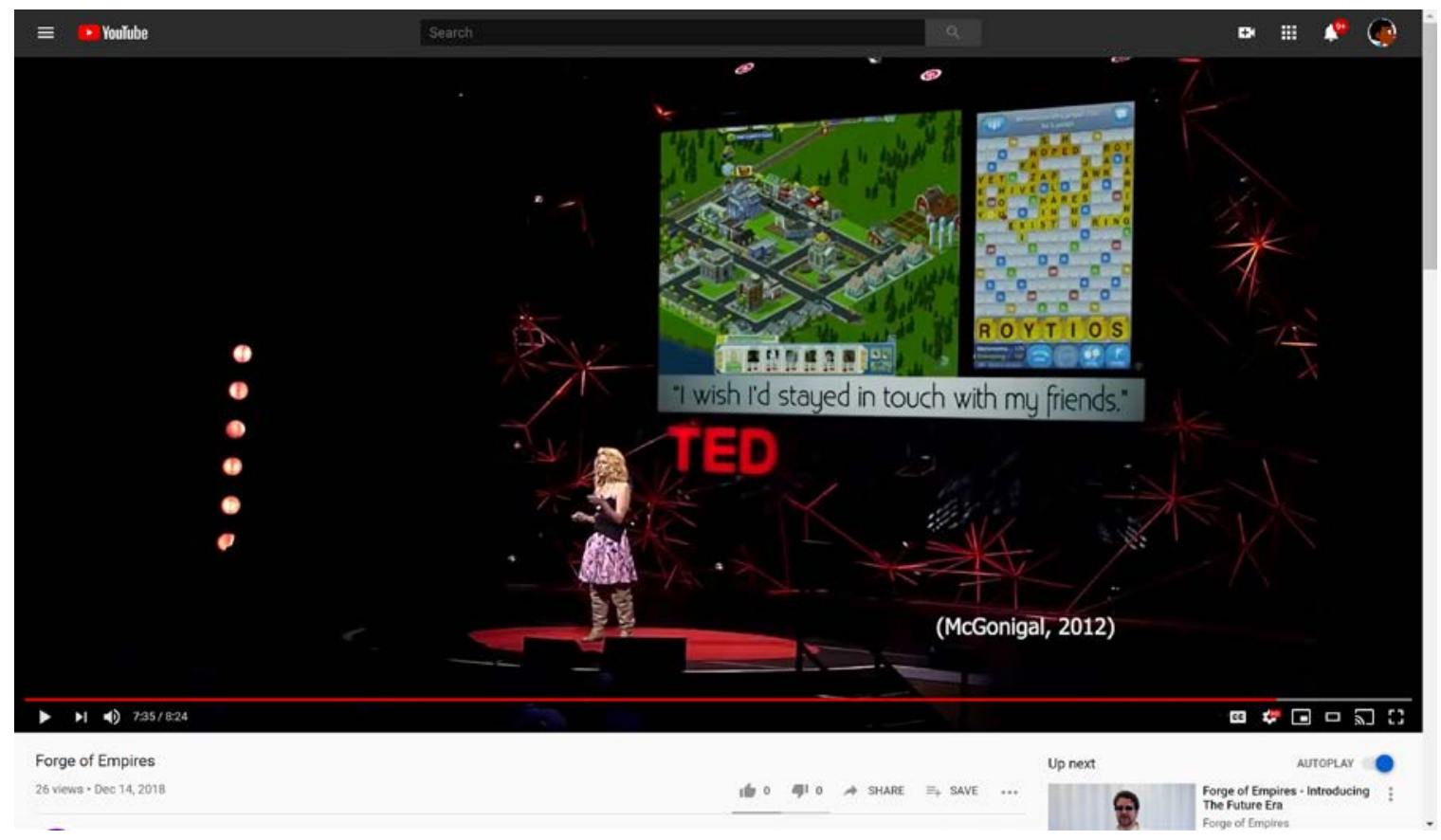

Image 1. Screenshot of a student's video essay about games.

The comic presented in Figure 2 demonstrates one student's understanding of the techniques employed by comic book creators. Judie (pseudonym), a senior English major, understood that comics are a visual medium with limited space for words so she chose to personify "knowledge" and "question" as two separate characters. This was a creative way for her to communicate information in a narrative mode, as is expected from comics. Another example of Judie's procedural knowledge of comic book techniques is visibly demonstrated with her use of different colors to differentiate between the characters of her story. She uses magenta for the unnamed student, blue for Knowledge, and red for Question, so that readers can easily identify them in each panel. Lastly, Judie demonstrates her declarative knowledge about the sequential storytelling nature of this medium. Students in my class were assigned a TEDx video in which McCloud (2005) explains: "Sequence is a very important aspect of comics. Comics present a kind of temporal map" (9:00); "every element of the work has a spatial relationship to every other element at all times" (11:45); and "as you move through space, you move through time" (12:15). While considering its educational potential, Judie writes: "Comics are very important because they allow students to read and understand at their own pace with their own kind of temporal map." 


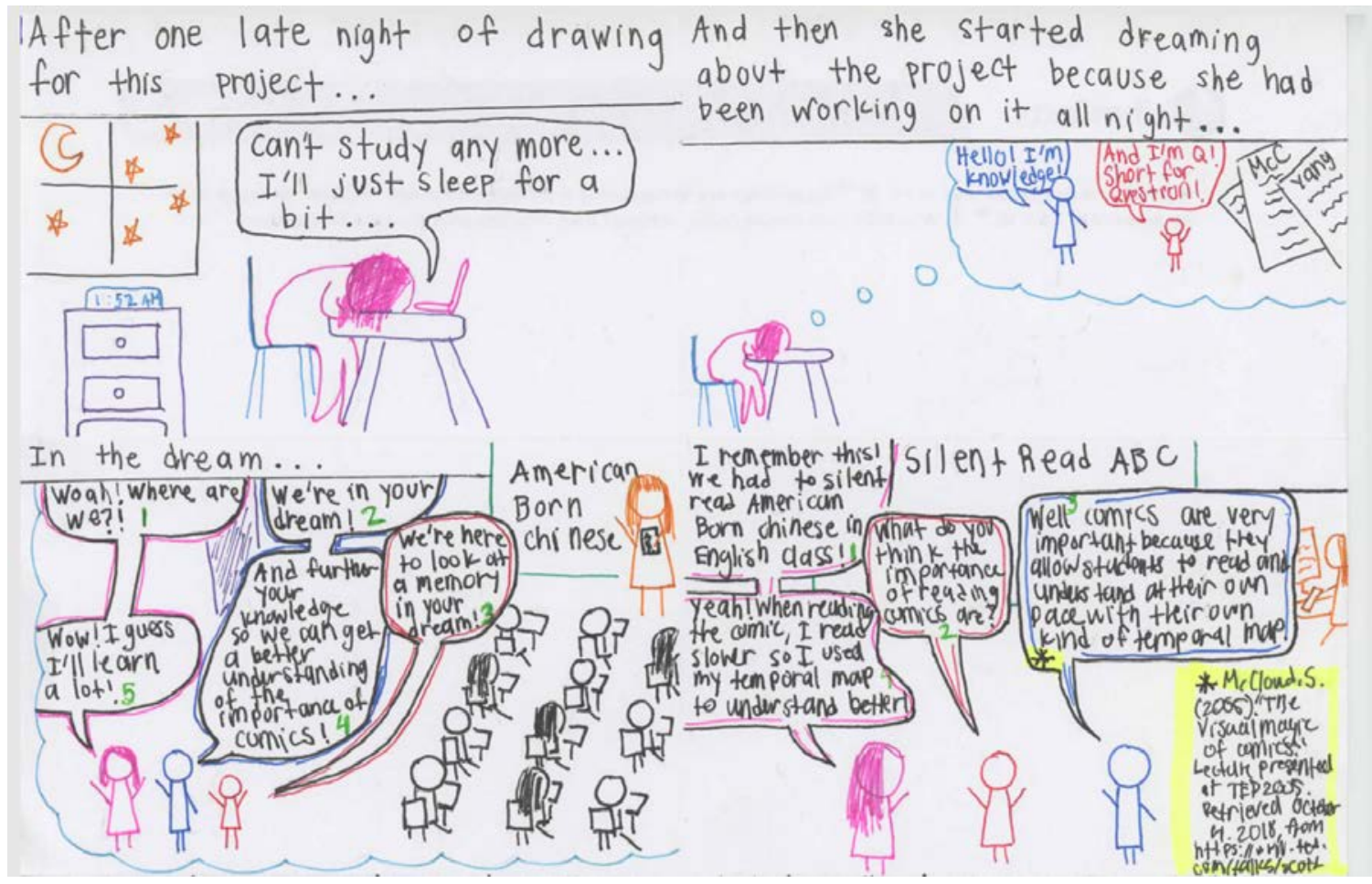

Image 2. Page from Judie's graphic narrative about comics.

\section{How might different people understand this message?}

A CRML approach to this question inspired many discussions about mainstream media's Eurocentric approach to telling stories. This targeted focus on White audiences can lead to different user experiences for diverse groups of consumers. Forge of Empires is one of many video games I assign in my class. The game's developers claim that it provides players with an "experience of all of history" (InnoGames, 2020). Yet, Eileen (pseudonym), a senior Communication major, commented on the lack of diversity amongst the game's initial 141 avatars (visual icons that serve as representations of each player). After searching for an avatar that could accurately represent her, she stated: "I found that there were only two female avatars that had a dark enough skin complexion paired with curlylooking hair." Mina (pseudonym), a senior Human Development major, also shared: "When I made my account, it automatically gave me a man ... the choices were mostly white males. This further aggravates the idea that girls cannot play video games." Conversely, Michael (pseudonym), a junior Applied Mathematics major, did not have the same negative experience. He commented: "The avatars used within the game seem relevant and fit the theme of the setting. It does a good job portraying the time period."

Educators should discuss the continued role that print books serve in our society. I have the students engage in discussions about the value of fiction and its ability to serve as a "gateway drug to reading" (Gaiman, 2013, para. 9) as well as its ability to help readers build empathy for others. In Figure 3 , Judie cites Hall and Lucal (1999) while her characters discuss how comics can help students 
empathize by allowing them "to connect their lives to parallel universes and see sociological perspectives." We discuss how students' learning styles, preferences, traits, and personal histories can contribute to variances in their experiences with the same content. Judie views differences in students' interpretations as positive. In her graphic narrative, she proposes a redesign of her past K-12 reading activities: "Instead of silent reading, I'd want more time to discuss the comic. I think discussing interpretations would allow me to understand more" (see figure 3). In figure 4, Diane (pseudonym), another senior English major, discusses her homeschooling experiences and the role that computers played in providing her with a customized learning experience.

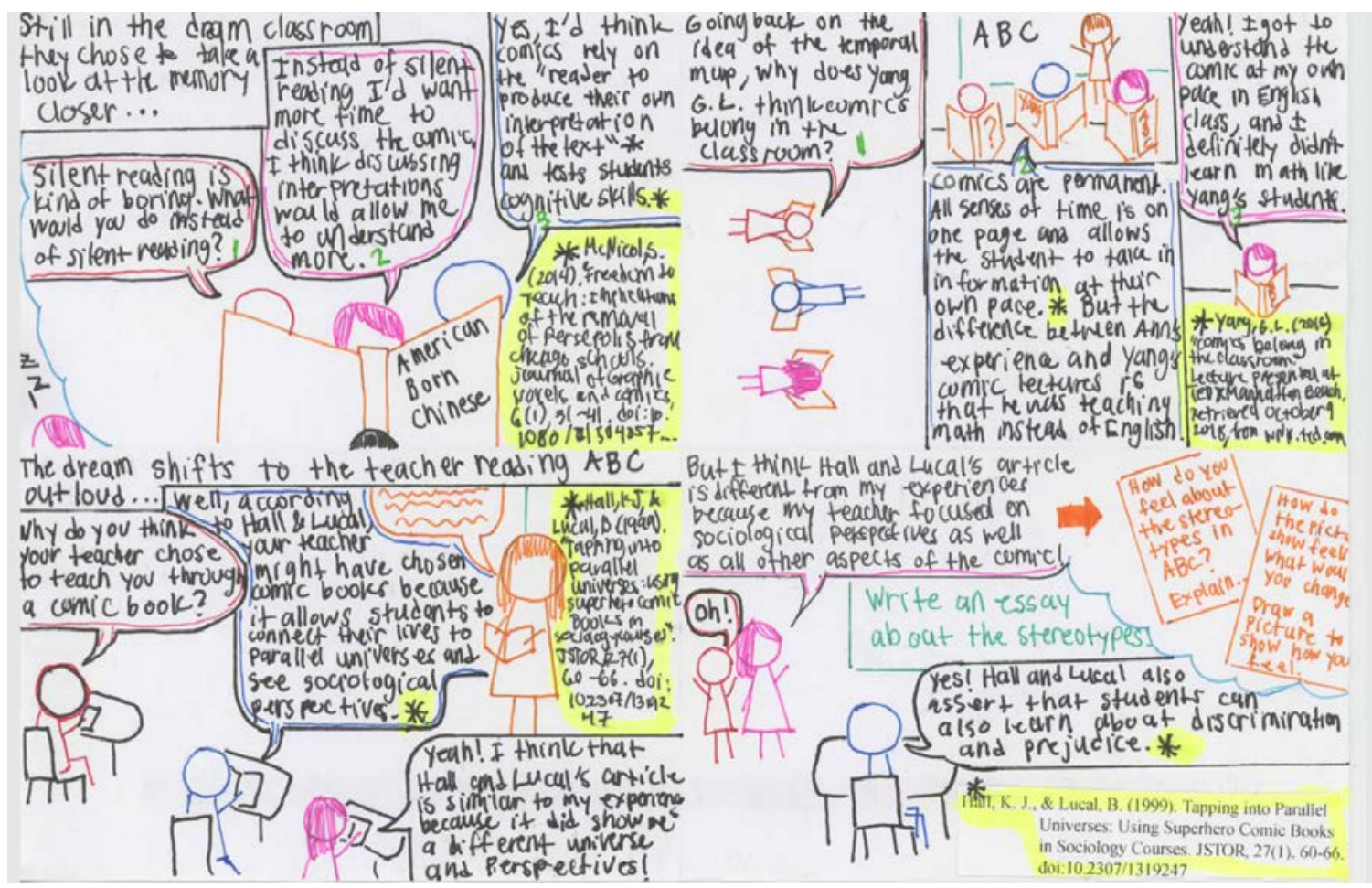

Image 3. Page from Judie's graphic narrative about comics. 


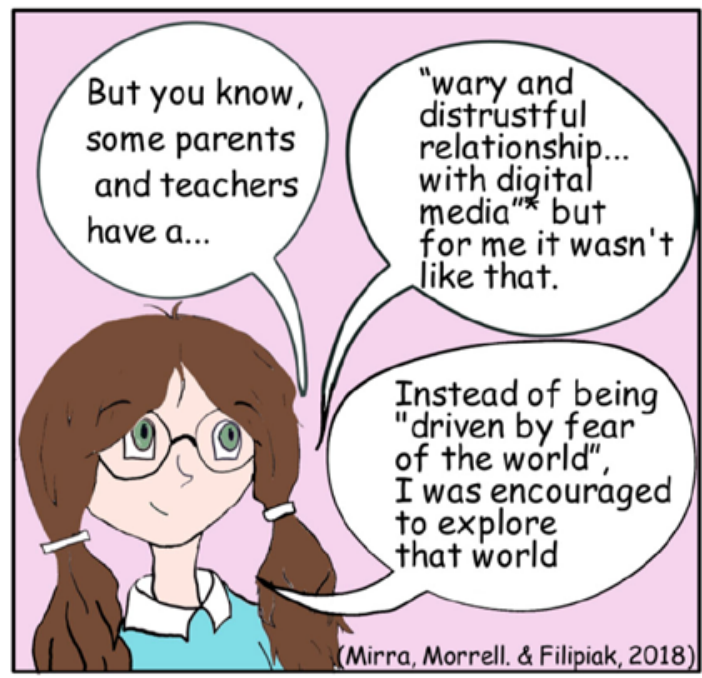

I would always look things up online, watch videos, and read anything I could find
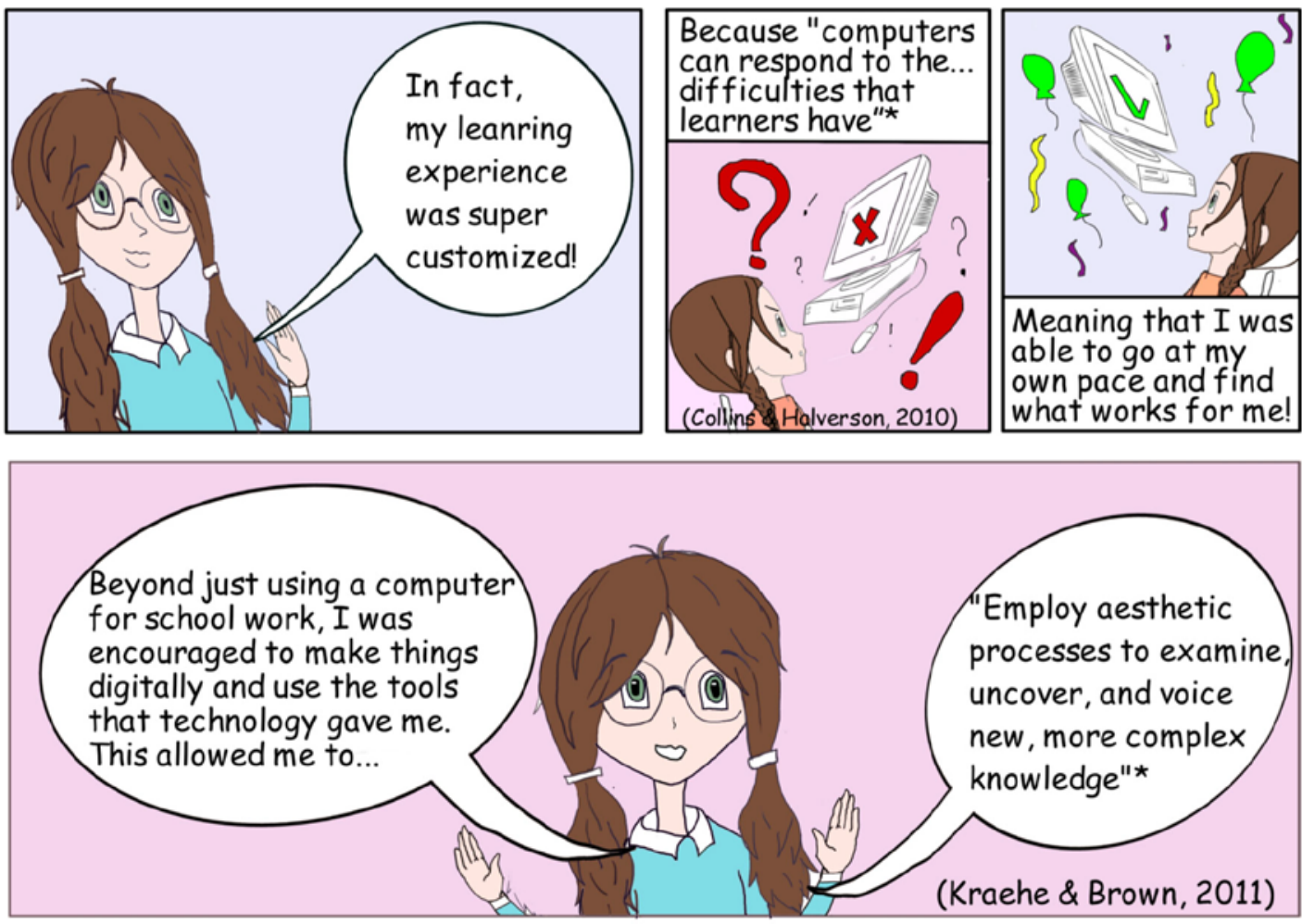

Image 4. Page from Diane's graphic narrative about technologies.

\section{Whose Lifestyles, Values, and Perspectives Are Included or Omitted?}

CRML reinforces the need to acknowledge media's role in the marginalization of historically oppressed groups. We examine the group-level values and perspectives that are embedded into our media and their effects on classroom experiences. Critical pedagogies, such as culturally relevant pedagogy (Ladson-Billings, 1995) and restorative English education (Winn, 2013), guide us in our discussions about the values and perspectives that are centered in our 
media experiences and those that are omitted. Furthermore, we examine various strategies used by producers during their attempts to create media that do not perpetuate stereotypes. The Bechdel-Wallace Test is one example that I introduce during our assessments of media content: "One, it has to have at least two women in it, who, two, talk to each other about, three, something besides a man. (Cima, 2015). I help them understand that the Bechdel-Wallace test serves as a popular tool for identifying when women are omitted, silenced, or depicted in reductive roles. However, we also recognize that it is an elementary approach that does not ensure that women are meaningfully incorporated into media narratives. Junior Human Development major Lucy's (pseudonym) graphic narrative (see figure 5) briefly mentions the social construction of gender, an additional concept that guides our conversations and investigations into whose values and perspectives are included and whose are left out. These activities are guided by questions suggested by Hall and Lucal (1999), for example: "How are cultural assumptions about the qualities that characterize womanhood and manhood reflected in the portrayals of the characters?" (p. 62).

\section{Why Was this Message Sent?}

Lastly, every course with CRML objectives must engage students in discussions about the financial forces that influence media messaging. It must also address the overrepresentation of White men in leadership positions at media organizations. My students are shown infographics that visually describe the small number of transnational corporations that own almost all of America's media organizations (Lutz, 2012). We discuss why these conglomerates seek our attention and how they profit from the advertising of products that are targeted at us (Raz, 2017). I present ethnoracial and gender demographic data about the executive leadership at these companies (Burns, Barton, \& Kerby, 2012; Smith, Choueiti, \& Pieper, 2016). We discuss why high income individuals benefit materially from meritocratic beliefs. We examine the rationalizations offered for the stereotypes used in media messages while also delving into why working-class Whites benefit psychically from racist media messaging (Alexander, 2012; Delgado \& Stefancic, 2017). We have nuanced discussions about the benefits of receiving targeted advertising campaigns for products that we really need. We also contrast that experience with the ramifications of repeated exposure to advertising that influences us to purchase items that we do not need. For instance, Samuel (pseudonym), a senior Neurobiology major, reflects on the 6-week-long online video game (Forge of Empires) assignment I give to the class:

I came to the quick realization that your overall progression is restricted by the integration of micro-transactions ... players can spend real currency to buy "diamonds" which instantaneously finishes the production of items ... [however], wait times become noticeably longer, while costs to bypass this mechanic become more expensive.

Moreover, Judie cites an assigned article as she writes about the importance of also looking beyond the game mechanics: "It is important [that] users critically analyze not only the game content itself, but the 'roles of the creator, the audience, 
and the stakeholders with interest in this power relationship' (Mirra, Morrell, \& Filipiak, 2018, p. 14)."

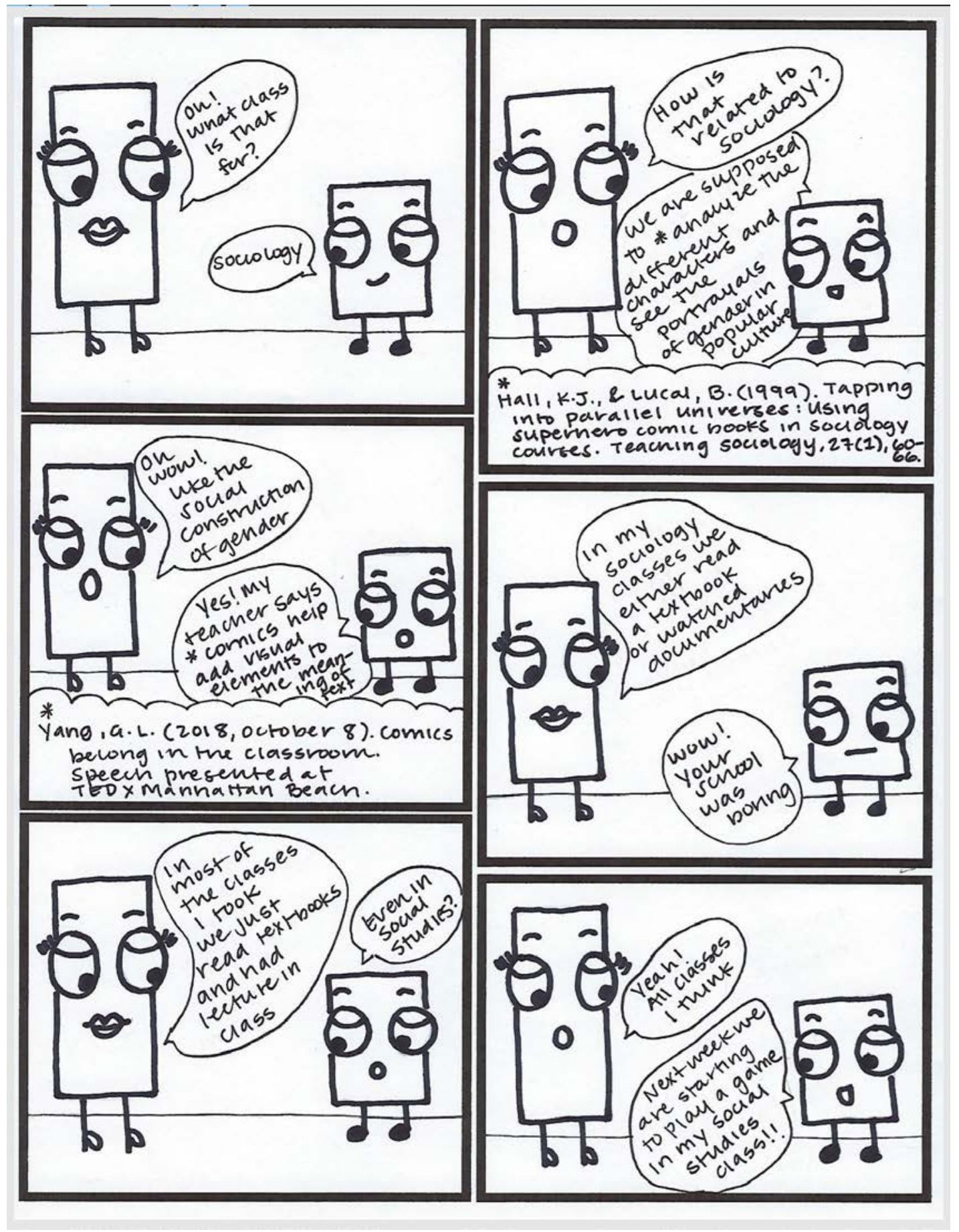

Image 5. Page from Lucy's graphic narrative about multimodal experiences. 


\section{Conclusion}

Arts-based inquiry is not immune to the biases that negatively influence other educational approaches. Systemic forms of discrimination inspire much of the problematic content in our media. They are also negative influences on students' classroom experiences (Howard, Flennaugh, \& Terry, 2012). CRML can assist teachers and students in navigating the complex issues that arise during media production and media consumption experiences by helping them (a) recognize negative stereotypical portrayals of historically oppressed groups in our media content, (b) question media producers' intentions, and(c) produce media content that does not perpetuate stereotypes.

Undergraduate education courses about educational technologies and media are excellent opportunities for teaching future teachers and other aspiring educational professionals about CRML. Technology costs and teachers' familiarities with technological media are important factors to consider alongside teachers' pedagogical beliefs (Rehmat \& Bailey, 2014) and attitudes about technology (Cullen \& Green, 2011). The need for pre-service and in-service teacher programs that incorporate CRML and arts-based inquiry into their curricula is especially urgent today. The social distancing, home schooling, and online classes that were in place during the coronavirus quarantine increased citizens' dependence on technological media for education and communication. The use of social media is increasingly relevant in these social contexts. Education programs should encourage professionals to adapt their curricula in ways that make these digital platforms viable tools during learning.

Today's social context calls for educational experiences that can help prepare students and teachers for the conflicts, collaborations, and growth that occur within our increasingly multicultural societies and classrooms. Worldwide multiracial protests over various social issues (e.g., police violence, climate warming, political corruption) are becoming increasingly common, yet our societies have also become politically polarized. These topics are relevant in CRML lessons. Morrell et al. (2013) recommend that we "allow students to have deep and thoughtful conversations about critical issues, but be prepared to handle students' real experiences and feelings" (p. 77). It is especially important that students be given more opportunities to express their concerns because the polarization of America has contributed to increases in their stress levels (Rogers, 2017). Artsbased inquiry provides students with creatively informative ways to engage in constructive dialogues around these topics. Lastly, investigations should explore how the evolving forms of racism, xenophobia, and biases that influenced inperson and online interactions during the pandemic may have exacerbated or introduced new forms of discrimination to classroom experiences. The results of these studies will be valuable to scholars and practitioners who seek to continuously improve and adapt pre-service and in-service teacher programs that implement CRML and arts-based inquiry practices. 


\section{References}

Alexander, M. (2012). The new Jim Crow: Mass incarceration in the age of colorblindness. The New Press.

Bagdikian, B. H. (2004). The new media monopoly. Beacon Press.

Bennett, S., \& Maton, K. (2010). Beyond the 'digital natives' debate: Towards a more nuanced understanding of students' technology experiences. Journal of Computer Assisted Learning, 26(5), 321-331. doi:10.1111/j.13652729.2010.00360.x

Blikstein, P. (2018). Pre-college computer science education: A survey of the field. Google LLC. Retrieved from https://goo.gl/gmS1Vm

Blume, C. (2020). Games people (don't) play: An analysis of pre-service EFL teachers' behaviors and beliefs regarding digital game-based language learning. Computer Assisted Language Learning, 33(1-2), 109-132.

Bogle, D. (2016). Toms, coons, mulattoes, mammies, and bucks: An interpretive history of blacks in American films. Bloomsbury Academic.

Burns, C., Barton, K., \& Kerby, S. (2012). The state of diversity in today's workforce: As our nation becomes more diverse so too does our workforce. Center for American Progress.

Butsch, R. (2011). Ralph, Fred, Archie, Homer, and the King of Queens: Why television keeps re-creating the male working-class buffoon. In G. Dines \& J. M. Humez. (Eds.), Gender, race, and class in media: A critical reader ( $3^{\text {rd }}$ ed.) (pp. 101-109). Sage.

Center for Media Literacy. (n.d.). Media literacy: A definition and more. Retrieved from http://www.medialit.org/media-literacy-definition-and-more

Cima, R. (2015, October 8). The comic strip that accidentally created a branch of feminist critical theory. PRICEONOMICS. Retrieved from: https://priceonomics.com/the-most-important-comic-strip-in-feminist/

Cullen, T. A., \& Green, B. A. (2011). Preservice teachers' beliefs, attitudes, and motivation about technology integration. Journal of Educational Computing Research, 45, 29-47.

Degand, D. (2019). Stereotypes vs. strategies for digital media artists: The case for culturally relevant media production. Theory Into Practice, 58(4), 368376.

Delgado, R., \& Stefancic, J. (2017). Critical race theory: An introduction (3 ${ }^{\text {rd }}$ ed.). NYU Press.

Dench, G. (Ed.). (2006). The rise and rise of meritocracy. Wiley-Blackwell.

Depura, K., \& Garg, M. (2012, December). Application of online gamification to new hire onboarding. In 2012 Third International Conference on Services in Emerging Markets (pp. 153-156). IEEE. 
Doerr-Stevens, C., \& Buckley-Marudas, M. (2019). Hearing knowledge into action: Mobilizing sound for multicultural imaginaries. International Journal of Multicultural Education, 21(1), 105-124.

Edith Cowan University. (2019, Aug 9). How to do a video essay. Retrieved from: https://ecu.au.libguides.com/video-essay/how-to-do-a-video-essay

Fernández, L. (2002). Telling stories about school: Using critical race and Latino critical theories to document Latina/Latino education and resistance. Qualitative Inquiry, 8(1), 45-65.

Gaiman, N. (2013, Oct 7). Why our future depends on libraries, reading and daydreaming. The Guardian. Retrieved from: https://www.theguardian. com/books/2013/oct/15/neil-gaiman-future-libraries-reading-daydreaming

Geyfman, V., Force, C. M., \& Davis, L. M. (2015). Women in business: Influences on the undergraduate major choices. Administrative Issues Journal: Connecting Education, Practice, and Research, 5(2), 51-63.

Giles, M. (2019). The influence of paired grouping on teacher candidates' attitude towards technology use and integration. Technology, Pedagogy and Education, 28(3), 363-380.

Global Action Project (n.d.) Impact, mission, and theory of change. Retrieved from https://www.global-action.org/our-story

Halverson, E. (2011, May 2). Art and stories. TEDxMadtown. Retrieved from: https://www.youtube.com/watch?v=DeeimXjwNgg

Hall, K. J., \& Lucal, B. (1999). Tapping into parallel universes: Using superhero comic books in sociology courses. Teaching Sociology, 27(1), 60-66.

Hansen, A. K., Dwyer, H. A., Iveland, A., Talesfore, M., Wright, L., Harlow, D. B., \& Franklin, D. (2017). Assessing children's understanding of the work of computer scientists: The draw-a-computer-scientist test. Proceedings from SIGCSE '17: The 2017 ACM SIGCSE Technical Symposium on Computer Science Education. ACM.

Hawkman, A. M., \& Van Horn, S. E. (2019). What does it mean to be patriotic?: Policing patriotism in sports and social studies classrooms. The Social Studies, 110(3), 105-121. doi:10.1080/00377996.2018.1553841

Hew, K. F., \& Tan, C. Y. (2016). Predictors of information technology integration in secondary schools: Evidence from a large scale study of more than 30,000 students. PLOS ONE, 11(12), 1-20.

Hicks, J., Winnick, L., \& Gonchar, M. (2019, April 19). Project Audio: Teaching students how to produce their own podcasts. The New York Times. Retrieved from: https://www.nytimes.com/2018/04/19/learning/lessonplans/project-audio-teaching-students-how-to-produce-their-ownpodcasts.html 
Howard, T. C., Flennaugh, T. K., \& Terry Sr, C. L. (2012). Black males, social imagery, and the disruption of pathological identities: Implications for research and teaching. Educational Foundations, 26, 85-102.

InnoGames. (2020). Forge of empires: City building strategy game. Retrieved from https://www.innogames.com/games/forge-of-empires/

Jackson, S. J., \& Welles, B. F. (2015). Hijacking \#myNYPD: Social media dissent and networked counterpublics. Journal of Communication, 65(6), 932-952.

Kellner, D., \& Share, J. (2007). Critical media literacy is not an option. Learning Inquiry, 1(1), 59-69.

Kraehe, A. M., \& Brown, K. D. (2011). Awakening teachers' capacities for social justice with/in arts-based inquiries. Equity \& Excellence in Education, 44, 488-511. doi: 10.1080/10665684.2011.610682

Kopcha, T. (2010). A systems-based approach to technology integration using mentoring and communities of practice. Educational Technology Research and Development, 58(2), 175-190.

Ladson-Billings, G. (1995). But that's just good teaching! The case for culturally relevant pedagogy. Theory into Practice, 34, 159-165.

Ligocki, D. T. (2017). So what IS critical media literacy? The differences between media literacy and critical media literacy. Paper presented at the International Critical Media Literacy Conference. Savannah, GA

Lutz, A. (2012, June 14). These 6 corporations control 90\% of the media in America. Retrieved from: https://www.businessinsider.com/these-6-corporationscontrol-90-of-the-media-in-america-2012-6

McCloud, S. (2005, February). The visual magic of comics. TED2005. Retrieved from: https://www.ted.com/talks/scott_mccloud_on_comics

Mirra, N., Morrell, E., \& Filipiak, D. (2018). From digital consumption to digital invention: Toward a new critical theory and practice of multiliteracies. Theory Into Practice, 57(1), 12-19.

Monaghan, D., \& Jang, S. H. (2017). Major payoffs: Postcollege income, graduate school, and the choice of "risky" undergraduate majors. Sociological Perspectives, 60(4), 722-746.

Morrell, E., Dueñas, R., Garcia, V., \& Lopez, J. (2013). Critical media pedagogy: Teaching for achievement in city schools. Teachers College Press.

National Coalition for Core Arts Standards. (March, 2018). The status of arts standards revision in the United States since 2014. Retrieved from https://www.nationalartsstandards.org/sites/default/files/NCCAS-StateReports-Since-2014.pdf

New London Group. (1996). A pedagogy of multiliteracies: Designing social futures. Harvard Educational Review, 66(1), 60-92. 
Polly, D., Mims, C., Shepherd, C. E., \& Inan, F. (2010). Evidence of impact: Transforming teacher education with preparing tomorrow's teachers to teach with technology (PT3) grants. Teaching and Teacher Education, 26, 863-870.

Purdue University. (n.d.). APA Style. Retrieved from: https://owl.purdue.edu/ owl/research_and_citation/apa_style/apa_style_introduction.html

Raz, G. (2017, October 13). Manipulation. TED Radio Hour. Retrieved from: https://www.npr.org/programs/ted-radio-hour/557417264/manipulation

Rehmat, A. P., \& Bailey, J. M. (2014). Technology integration in a science classroom: Preservice teachers' perceptions. Journal of Science Education and Technology, 23, 744-755.

Rhoades, M. (2020). A contemporary arts-based approach to critical multimodal literacy. Language Arts, 97(3), 178-185.

Rogers. J. (2017). Teaching and learning in the age of Trump: Increasing stress and hostility in America's high schools. UCLA IDEA.

Share, J. (2015). Media literacy is elementary: Teaching youth to critically read and create media ( $2^{\text {nd }}$ ed.). Peter Lang Publishing, Inc.

Smith, S. L., Choueiti, M., \& Pieper, K. (2016). Inclusion or invisibility? Comprehensive Annenberg report on diversity in entertainment. Institute for Diversity and Empowerment at Annenberg.

Sohoni, T. (2019). Harnessing the power of social media in the classroom: Challenging students to create content to share on social media sites to improve learning outcomes, Journal of Criminal Justice Education, 30(3), 389-406. doi:10.1080/10511253.2018.1538420

Tondeur, J., van Braak, J., Ertmer, P. A., \& Ottenbreit-Leftwich, A. (2017). Understanding the relationship between teachers' pedagogical beliefs and technology use in education: A systematic review of qualitative evidence. Educational Technology Research and Development, 65(3), 555-575.

Tondeur, J., van Braak, J., Siddiq, F., \& Scherer, R. (2016). Time for a new approach to prepare future teachers for educational technology use: Its meaning and measurement. Computers \& Education, 94, 134-150.

Wargo, J. M. (2019). Lights! Cameras! Genders? Interrupting hate through classroom tinkering, digital media production and [Q]ulturally sustaining arts-based inquiry. Theory Into Practice, 58(1), 18-28.

Winn, M. T. (2013). Toward a restorative English education. Research in the Teaching of English, 48(1), 126-135.

Yosso, T. J. (2002). Critical race media literacy: Challenging deficit discourse about Chicanas/os. Journal of Popular Film and Television, 30(1), 52-62.

Yuen, N. W. (2016). Reel inequality: Hollywood actors and racism. Rutgers University Press. 


\section{Author Contact}

Darnel Degand, ddegand@ucdavis.edu

University of California, Davis, School of Education

One Shields Ave, School of Education Building, Davis, CA U. S. A. 95616 